International Journal of Biology, Pharmacy

and Allied Seiences (IJBPAS)

'A Bridge Betusen Caboratory and Qqude'

WwW.ijbpas.com

\title{
NEGLECTED UNREDUCED FRACTURE DISLOCATION ANKLE
}

\section{S.THIRUGNANASAMBANTHAN ${ }^{*}$, PRAYANK HISHIKAR ${ }^{2}$ AND R.VIJAYARAGHAVAN ${ }^{3}$}

1: Senior Resident in orthopaedics, Sri Lakshminarayana Institute of Medical Sciences, Pondicherry

2: Junior Resident in orthopaedics, Sri Lakshminarayana Institute of Medical sciences, Pondicherry

3: Associate Professor in Orthopaedics, Sri Lakshminarayana Institute of Medical Sciences, Pondicherry

*Corresponding Author: Dr. S.Thirugnanasambanthan: E Mail: drthiru ortho@yahoo.co.in

Received $18^{\text {th }}$ Oct. 2020; Revised $16^{\text {th }}$ Nov. 2020; Accepted $14^{\text {th }}$ Dec. 2020; Available online $1^{\text {st }} \mathrm{Jan} .2021$

\section{https://doi.org/10.31032/IJBPAS/2021/10.1.1015}

\section{ABSTRACT}

Neglected unreduced ankle fracture dislocation is a rare presentation and seldom seen. In India people still prefer to take native treatment from the traditional bone setter and later come to hospital with complications. Because of the late presentation to the hospital, early reduction of the dislocation is not achieved, resulting in poor prognosis. Dislocations have to be reduced at the earliest to prevent complication. In old unreduced dislocation cases the soft tissue release has to be carried out from the posterior, lateral and anterior medial aspects of the ankle. It is difficult to surgically correct this old unreduced dislocation due to soft tissue contractures, mal uniting fibula fracture and sometimes interposition of postero medical structures into the ankle joint. Preserving the soft tissue attachments and the periostium is important to prevent cartilage damages and avascular necrosis of the Talus. We present a case of 1 and $1 / 2$ months old neglected unreduced fracture fibula with syndesmotic injury and posterolateral dislocation of the talus in relation to the distal tibia. The clinical presentation and surgical treatment are discussed.

Keywords: fracture fibila, fracture dislocation, syndesmosis, medial collateral ligaments,

ORIF, plate fixation, syndesmotic screw, Bosworth 


\section{INTRODUCTION}

Old unreduced fracture dislocation of ankle is rarely seen here and its reduction is still an emergence surgical procedure so as to minimize the complication. Eventhough patients go to hospitals for first aid they prefer to take further treatment from the traditional bone setters, where the pop is removed, fracture or the dislocation is manipulated and splinted with herbs, sticks and bandages. Later they develop skin necrosis, joint contractures, neuro-vascular compromise and mal or non-union with compressive damage to the articular cartilages of the dome of Taus and the distal tibia [1-4]. The treatment of such unreduced fracture dislocation is very challenging for the orthopaedic surgeon. Extensive soft tissue release has to be carried out in all aspects and care should take to protect the neuro vascular structures and preventing the deep medial tendons to get entrapped inside the joint during the process of reduction and fixation. several case reports and articles are published about the mechanism of injury, the extent of soft tissue injuries, contracture, complications and the difficulties faced by the surgeons [5-7].

We present our case of a patient with RIGHT fibular fracture with ankle dislocation successfully treated by Open Reduction Internal Fixation to RIGHT ankle joint with $\mathrm{K}$-Wire and distal $1 / 3^{\text {rd }}$
Fibular plate osteosynthesis with syndesmotic screw fixation under Spinal Anaesthesia.

\section{Case Report}

We present a case of a 33 years old male patient with 1 and $1 / 2$ months old neglected unreduced fracture dislocation of Right ankle. He gives a history of twisting injury to his Right ankle following a fall from a motorcycle. Initially patient was taken to a government hospital where he was diagnosed with distal $1 / 3^{\text {rd }}$ Fibula fracture without any dislocation for which Below knee POP slab was applied (Figure 1). Later patient went to a native bone setter where his POP slab was removed and manual manipulation was done and the patient was given splints and native bandages. As per the traditional bone setters he was ambulant with a walking stick. During this native treatment period patient had severe pain in the ankle and persistent swelling.

When the native splints and bandages where removed after 6 weeks, patient noticed deformity in the ankle region with swelling. He then came to this Institution and radiograph of RIGHT ankle was taken which showed posterior lateral dislocation of RIGHT Talus in relation to the distal end of tibia [ankle joint] with non-uniting fibula long oblique fracture (Figure 4). 
On clinical examination there was an anterior angulation deformity at the ankle region (Figure 3), ankle swollen, tender and the range of movement was restricted painfully. Sensation was intact, Dorsalis pedis pulse feeble and active toe momentspresent. Our treatment included Open Reduction Internal Fixation RIGHT ankle joint with $\mathrm{K}$-Wire and distal $1 / 3^{\text {rd }}$ Fibular plate osteosynthesis with syndesmotic screw fixation. Post-operative radiographs (Figure 5) were satisfactory and patient was followed up for 5 month during which patient improved symptomatically with good improvement.

\section{METHODS}

All the necessary blood investigations were done and the $\mathrm{x}$ ray of the ankle Antero posterior, Lateral and Mortise views were taken. The joint was evaluated and the plan and approaches were discussed. Patient supine under spinal anesthesia, the Right lower limb prepared under aseptic precaution. Through posterio lateral approach, the fibula fracture site exposed, removing the fibrous tissues and the fracture margins were freshened and the canal opened.

The granulation tissues and the fibrous tissues were removed from the introessous space and slowly advanced inferiorly to the joint clearing the damaged anterior and posterior Tibio fibular ligaments [syndemosis]. The capsule was also removed along with the granulation tissue between the Talus and the fibula in both anterio lateral and posterior lateral to the ankle joint. The granulation tissue between the Talar dome and the articular surface of the distal tibia was removed carefully. Anterio medial approach was used to clear the soft tissue in the medial gutter. Another posterior medial approach was used to release the granulation and the soft tissues from the postero medial and the posterior aspect of the ankle joint. Care was taken to identify and protect the tendons and the neuro vascular structures while meticulously releasing the soft tissue around the ankle joint.

After the thorough soft tissue release the ankle joint was able to reduce into its anatomical position with difficulty. Fibula fracture was fixed with $3.5 \mathrm{~mm}$ system 10 holed semi tubular plate and with cortical screws. $4 \mathrm{~mm}$ fully threaded cancellous screw was used as a syndesmotic screw passed from lateral to medial through the plate. The syndesmosis was stable after the plate and the syndesmotic screw fixation. We applied two $2.5 \mathrm{~mm}$ thick $\mathrm{K}$ wire from the calcaneum through the Talus and driven into the distal Tibia to have a stable joint. Surgical wound was closed in layers and below knee POP slab was applied. Intraoperatively prophylactic antibiotics were 
used according to the local guidelines [810].

\section{RESULTS}

Regular wound inspection and dressing was done. All the sutures was done on the $12^{\text {th }}$ pod as we wanted a good healing of the surgical wound. Immobilization of the ankle was maintained up to 4 weeks. Patient was ambulated non weight bearing with walker support. X ray was taken after 4 weeks which showed the ankle in good reduced position and the implants were intact without any signs of infection. POP slab was removed and the $\mathrm{K}$ wire removed after 4 weeks. Passive and active range of movement of the ankle was started. Partial weight bearing started after 6weeks. Full weight bearing encouraged after 12 weeks. Serial radiographs were obtained at regular interval and the result was found to be satisfactory, patient improved symptomatically with good [Dorsiflexion upto 20 degrees and plantar flexion upto 30 degrees possible].

\section{DISCUSSION}

This is a case of fracture dislocation of the ankle which was unreduced for the past 1 and $1 / 2$ months following the manipulation by the inexperienced traditional bone setter. The initial trauma did not cause a dislocation in the ankle but only a fracture in the fibula along with a degree of syndesmotic injury with a Danis-
Weber type c. this is evident from the initial $x$ ray image immediately following the trauma. The dislocation of the ankle with severe syndesmotic injury was caused by the traditional bone setter [iatrogenic] while trying to reduce the fracture. the patient presented to us with weber type c fracture fibula, syndesmotic injury with interosseous injury and postero lateral dislocation of Talus in relative to the distal tibia [Lauge-Hansen supination-external rotation type 4] which is evident with the $\mathrm{x}$ ray of the ankle AP/Lat/Mortise views following the native treatment [11-15].

This is similar to the Bosworth fracture dislocation but with some variation both in the presentation and the mechanism of injury. The reduction required elaborate soft tissue release with an additional antero medial incision to remove the capsule and the granulation tissues from the medial gutter. Fixing the fibula fracture along with syndesmotic screw is mandatory for the stability of the syndesmosis. Prolonged physiotherapy is required to mobilize the joint for good results [16-21].

\section{CONCLUSION}

In conclusion, this type of neglected unreduced fracture dislocation is difficult to treat and require expertise. It is an example of mismanagement by the native bone setters. Open reduction and internal fixation of the fracture fibula with extensive soft tissue release is important for the reduced 
of the dislocation. Perioperative fixation is very crucial. Early surgical examination of the syndesmosis for its reduction and fixation gives good results. stability is mandatory and the syndesmotic

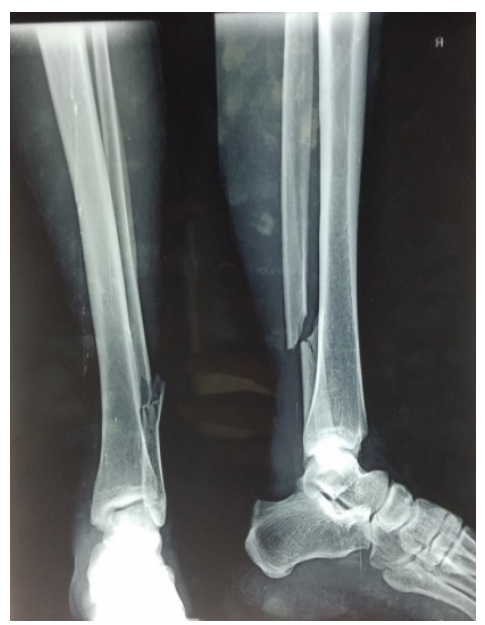

Figure 1: Initial $x$ ray of the ankle immediately following the truma

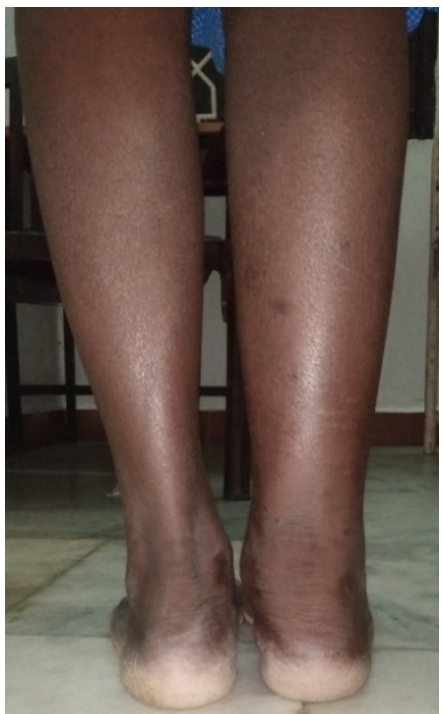

Figure 1 : Inspection from back showing increased intramalleolar distance over RIGHT ankle

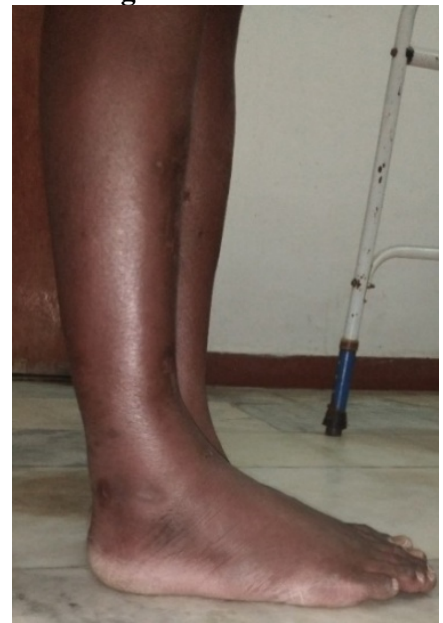

Figure 2 : inspection from side showing deformity over RIGHT ankle 


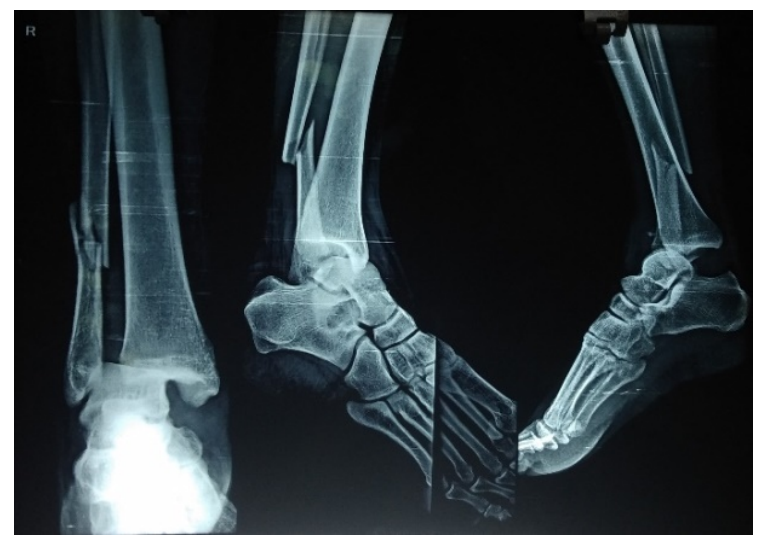

Figure 4: Antero-posterior and lateral radiograph RIGHT ankle after manipulation by a native bone setter. 1 and $1 / 2$ months following the trauma

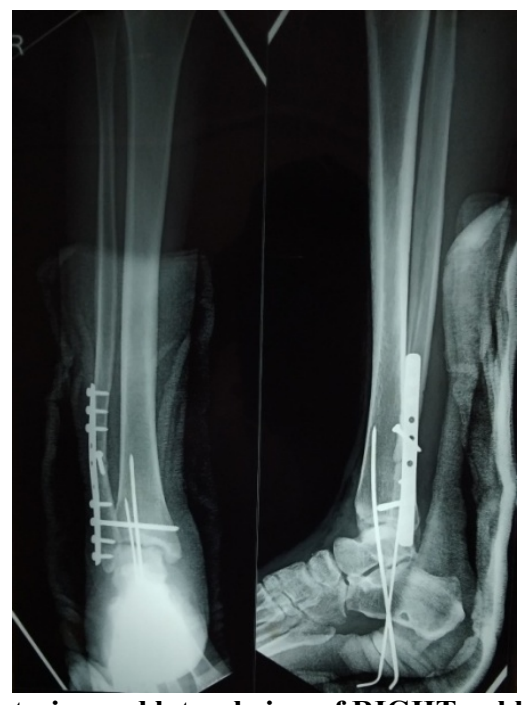

Figure 5: Post-op radiograph anteroposterior and lateral view of RIGHT ankle joint showing and distal $1 / 3^{\text {rd }}$ Fibular plate osteosynthesis with syndesmotic screw fixation

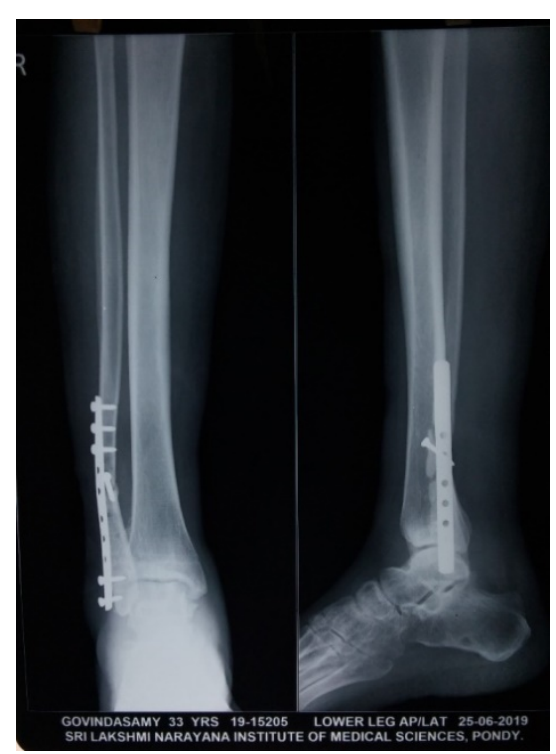

Figure 6: 5 months follow up $\mathrm{x}$ ray 


\section{REFERENCES}

[1] Daruwalla, J.S. Medial dislocation of the ankle without fracture: a case report. Injury. 1974; 5: 215-216.

[2] Fonda, M.P. Dislocation of the tibiotalar joint without fracture: an unusual ski injury. J Bone Joint Surg Am. 1952; 24 : 662-664.

[3] Krishnamurthy, S., Schultz, R.J. Pure posteromedial dislocation of the ankle joint (A case report) .Clin Orthop Relat Res. 1985; 68-70 (Dec).

[4] Wilson, A.B., Toriello, E.A. Lateral rotatory dislocation of the ankle without fracture. J Orthop Trauma. 1991; 5: $93-$ 95.

[5] Colville, M., Colville, M.R., Colville, J.M., Manoli, A. 2nd. Posteromedial dislocation of the ankle without fracture. J Bone Joint Surg Am. 1987; 69: 706711.

[6] Rivera, F., Bertone, C., De Martino, M., Pietrobono, D., Ghisellini, F. Pure dislocation of the ankle: three case reports and literature review. Clin OrthopRelat Res. 2001; 179-184. (Jan).

[7] Scott, J.E. Dislocations of the ankle without fracture. Injury. 1974; 6: 63-66.

[8] Fahey, J.J., Murphy, J.L. Talotibial dislocation without associated fracture. Surg Clin North Am. 1965; 45: 80-101.

[9] Segal, L.S., Lynch, C.J., Stauffer, E.S. Anterior ankle dislocation with associated trigonal process fracture (A case report and literature review). Clin Orthop. Relat Res. 1992; 171-176 (May).
[10] Wilson, M.J., Michhele, A.A., Jacobson, E. Ankle dislocation without fracture. J Bone Joint Surg. 1939; 21A: 198-204.

[11] D'Anca, A.F. Lateral rotatory dislocation of the ankle without fracture (A case report) . J Bone Joint Surg Am. 1970; 52: 1643-1646.

[12] Toohey, J.S., Worsing, R.A. Jr. A longterm follow-up study of tibiotalar dislocations without associated fractures. Clin Orthop Relat Res. 1989; 207-210 (Feb).

[13] Uyar, M., Tan, A., Isler, M., Cetinus, E. Closed posteromedial dislocation of the tibiotalar joint without fracture in a basketball player. Br J Sports Med. 2004; 38: $342-343$.

[14] Gaebler, C. Fractures and dislocations of the carpus. in: R.W. Bucholz, J.D. Heckman, C. Court-Braun (Eds.) Rockwood and Green's Fractures in Adults. ed 6. Lippincott Williams and Wilkins, Philadelphia; 2006: 856-908.

[15] Bosworth D.M. Fracture-dislocation of the ankle with fixed displacement of the fibula behind the tibia. J. Bone Joint Surg. Am. 1947 Jan; 29(1): 130-135. [PubMed] [Google Scholar].

[16] Perry C.R., Rice S., Rao A., Burdge R. Posterior fracture-dislocation of the distal part of the fibula. Mechanism and staging of injury. J. Bone Joint Surg. Am. 1983Oct; 65(8): 1149-1157. [PubMed] [Google Scholar].

[17] Khan F., Borton D. A constant radiological sign in Bosworth's fractures: 
“the Axilla sign" Foot Ankle Int. 2008;

29: 55-57. [PubMed] [Google Scholar].

[18] Yeoh C.S., Tan G.M. Bosworth fracturedislocation of the ankle: a case report. J. Orthop. Surg. (Hong Kong) 2013 Aug; 21(2): 249-252. [PubMed] [Google Scholar].

[19] Beekman R., Watson J.T. Bosworth fracture-dislocation and resultant compartment syndrome. A case report. J. Bone Joint Surg. Am. 2003 Nov; 85-A (11): 2211-2214. [PubMed] [Google Scholar].

[20] Szalay M.D., Roberts J.B. Compartment syndrome after Bosworth fracturedislocation of the ankle: a case report. J. Orthop. Trauma. 2001 May; 15(4): 301303. [PubMed] [Google Scholar].

[21] Bartonícek J., Fric V., Svatos F., Lunácek L. Bosworth-type fibular entrapment injuries of the ankle: the Bosworth lesion. A report of 6 cases and literature review. J. Orthop. Trauma. 2007 Nov-Dec; 21(10): 710-717. [PubMed] [Google Scholar. 